\title{
Evolutionary-stable strategies with increasing and decreasing marginal utilities in the Ausubel auction
}

\author{
Asuncion Mochon, David Quintana, Yago Saez, Pedro Isasi
}

\begin{abstract}
A genetic algorithm has been developed to solve bidding strategies in a dynamic multi-unit auction: the Ausubel auction, with independent private values and without dropout information. The genetic algorithm aims to maximize each bidder's payoff. To this end two experimental environments have been tested with decreasing and increasing marginal utilities. The bidding strategies are analyzed, along with their effects on revenue and efficiency. With decreasing marginal utilities the computational experiments yield to sincere bidding as the evolutionary-stable strategy, which is also the weakly dominant strategy and the ex post perfect equilibrium. Nevertheless, with increasing marginal utilities there is no theory model developed in order to find the equilibrium. Therefore, the challenge of this work is to study the auction outcome where theoretical predictions are unknown. The genetic algorithm finds bidding sincerely as the evolutionarystable strategy with increasing marginal utilities.
\end{abstract}

\section{INTRODUCTION}

$\mathrm{M}$ ULTI-UNIT auctions are widely used in different markets for selling items like spectrum rights, treasury bills, electricity, emission permits, etc. In multiple-object environments where individual bidders may demand more than one homogeneous item, the seller must choose among a wide variety of auction formats. The most common multiunit auctions with sealed-bid formats are the discriminatory auction, the uniform-price auction and the Vickrey auction. On the other hand, in the open format the underlying auctions are the Dutch (or open descending price) auction, the English (or open ascending-price) auction and the Ausubel auction (a dynamic version of the Vickrey auction).

Auction theory is founded on the dual assumptions of rational behavior and equilibrium. It gives players some prescriptive guidance of how they should play. Nevertheless, a number of social scientists challenge the rationality assumption, and argue that it should not be taken for granted. Therefore, an alternative must be reached in order to search for the best strategies but without assuming perfectly calculating rationality on players. Biological theory of evolution might be a key point to this challenge.

Biological theory rests upon three fundamentals: heterogeneity, fitness and selection. An important part of

This article has been financed by the Spanish founded research MCyT project OPLINK, Ref: TIN2006-08818-C04-02

Asuncion Mochon is with the Department of Applied Economics, UNED University, Madrid, Spain (amochon@cee.uned.es)

David Quintana, Yago Saez and Pedro Isasi are with the Department of Artificial Intelligence, University Carlos III of Madrid, Spain (david.quintana, yago.saez, pedro,isasi@uc3m.es ) animals' behaviour is genetically determined by one or more genes (genotype) that govern a particular pattern of behaviour (phenotype or strategy). The pool of genes ensures heterogeneity of phenotypes in the population, for which success is given by a quantitative measure called fitness value. The fitness of a particular strategy is defined as its aggregate or average payoff in its matching with all the strategies in the population. The process of selection ensures that the fitter phenotypes become relatively more numerous in the next generation, and may be leads, eventually, to a stable state. Changes produce new genetic mutations that can guide to a new and fitter phenotype and successfully invade a population, i.e., spreading till became a significant proportion of the population. A particular phenotype is evolutionary stable if any mutant cannot invade its population successfully. Therefore, the strategy played by an evolutionary stable phenotype is called an evolutionarystable strategy (ESS), the strategy that will persist in the population if played by all the existing phenotypes, see [1].

A recent method of analyzing strategies on auctions using evolutionary games is by the means of systems of artificial adaptive agents (AAA). The analysis of these systems gives new approaches to the understanding of the economic and social behaviour of auctions. In this way, the use of machine learning systems can help in the finding of optimal strategies or in the evaluation, from different points of view, of the auction itself with respect to other possible auctions. In this context, genetic algorithms (GAs) are a good learning method. GAs were developed by Holland [2] as a robust method of adaptive searching, learning and optimization in complex problem domains. This method has been applied for describing the learning behavior of agents in auctions: [3]-[10], etc.

This paper is focused on a particular specification of a multiple-object ascending-clock auction developed by [11], [12], which is usually known as the Ausubel auction. In this auction, with private values and diminishing marginal utilities, sincere bidding by all bidders is an ex post perfect equilibrium, yielding to efficient outcome. Nevertheless, with increasing marginal utilities the theoretical equilibrium has not been developed yet.

The aim of this work is to use GAs to study the bidders' behaviour searching for the strategy that maximize their payoff, for both, increasing and decreasing marginal utilities. The challenge is to find out whether the best strategies can be achieved automatically by means of GAs. 
Furthermore, the auction is analysed in terms of revenue and efficiency that yields.

There are other authors that have studied this auction format, [13]-[14], and made a modification of the Ausubel auction with asymmetric bidders and interdependent values. This modification was made in order to get an efficient ascending multiple auction. Bikhchandani [15] showed that the auction corresponds to the implementation of a marginal product pricing equilibrium via the primal-dual algorithm. Additionally, this auction format has been frequently compared with other multi-unit auctions. [16] compared this auction experimentally with the static multi-unit auction analysed by [17] both for private and common value. [18], [19] studied these two auction mechanisms and also included the alternative of with and without dropout information in the Ausubel format. [20] considered four different auction formats: sealed-bid Vickrey auction, Ausubel auction with dropout information provided, survival auction and two-stage survival auction. They conducted an experimental study to compare the different outcomes. [21] evaluated pros and cons of the standard ascending-clock auction and the Ausubel auction in a setting where the authorities wished to allocate exclusive rights such as emission permits efficiently, and where allocation of these rights has consequences for the level of production as well as market shares. [22] presented a laboratory experiment of different multi-unit auction mechanisms. These authors tested whether expected demand reduction occurs in open and sealed-bid uniform-price auctions. Moreover, they analysed the revenue equivalence for these auctions as well as for the Ausubel, the Vickrey and the discriminatory sealed-bid auction.

The remainder of this article is structured in the following manner. Section 2 presents good reasons for relaxing the decreasing marginal utilities assumption and consider that bidders can have increasing marginal utilities. A definition of the auction model is given in section 3 . Section 4 describes the experimental environment, the bidding strategy for each environment and the fundamentals of the bidding algorithm. Section 5 evaluates the experimental results for both increasing and decreasing marginal utilities by studying the bidders' strategy, revenues and efficiency. Finally, in section 6 the main conclusions and future work are presented.

\section{WHY INCREASING MARGINAL UTILITIES?}

Traditional utility theory assumes that people are rational agents with diminishing marginal utilities. This involves that, as additional units of a good are consumed, they report a lower marginal utility, the economic "law of diminishing marginal utility". These models also presume that tastes are stable overtime and among people. Nevertheless, these theories do not enclose the whole amalgam of possibilities for the consumers' utilities. They do not allow time to change the consumers' tastes. Hence, explanations for economics behaviour (including changes in their characters) can not be reached.

Reference [23] presented an alternative theory of consumer choice explained by using a generalized calculus of utility-maximizing behaviour without assuming that tastes remain stable. These authors take categories of behaviour commonly held to demonstrate changes in tastes or to be explicable only in terms of such changes, and show that they are reconcilable with their assumption of stable preferences.

Frequently tastes change with time. However, people can be "addicted" to certain goods such as caffeine, cigarettes, alcohol or drugs, of which consumption over a significant amount of time often increase the craving of consuming more. There are also certain goods that require training or education, such as books, music or even a relation ship, of wich consumption over time has the same effect. The explanation for these attitudes in economic terms is that people have increasing marginal utilities over time because taste change on their favor. [23] define the term "consumption capital" as the consumption accumulation by the consumer, which can be "beneficial" addiction like reading or "harmful" addiction like having drugs.

Later on, economist accepted the possibility that, in some cases, preferences functions will demonstrate increasing returns to scale, [24]. If an individual consumes or acquires more of a good, and the marginal utility of additional amounts of that good increases, then, the individual's preferences reveal increasing return to scale. Individual preferences may reflect increasing returns to scale when increasing amounts can change the use of the good or resource. For example, having more tickets for going to a concert will probably have diminishing marginal utility if the consumer can only use them to go to the same concert over and over again. Nevertheless, these individual can have increasing marginal utility if having one ticket means listening to the concert, two means having a date, three means having a party, and so on.

According to prospect theory [25], the same level of wealth can imply poverty or riches for different persons, depending on their initial assets. Therefore, value should be treated as a function in two arguments, measured as changes (positive or negative) from a reference point. The reference points create perceived regions of gain and loss that take on non-linear preference functions. An important characteristic of attitudes to changes in welfare is that, the annoyance that one experience in losing a sum of money appears to be greater than the pleasure associated with gaining the same amount. Thus, these authors propose a value function, which is defined on deviations from the reference point; generally concave for gains, commonly convex for losses, and steeper for losses than for gains. With this utility function [26] showed how this preference function is likely to reflect increasing marginal utility, and decreasing marginal utility. Moreover, theses authors studied the effect of non-linear preferences on negotiated settlements. They tested whether the shape of negotiators' preferences influenced the negotiated outcomes. The shape of the preferences analysed was: linear, increasing and decreasing marginal utility. 
Results supported a strong main effect for negotiators' preferences on the outcomes. To sum up, increasing marginal utilities do exist in real life. Therefore, to analyze the effect of these preferences in the outcome of an auction can be helpful.

\section{UNDERSTANDING THE AUSUBEL AUCTION MECHANISM}

This paper focuses on a particular specification of rules for what might be referred to generically as an "ascendingclock auction". The alternative ascending-bid auction or Ausubel auction was developed by Ausubel [11], [12]. The auction starts with a low price, with price increasing continuously in each round $(l)$. Bidders start out actively bidding on all units demanded, choosing what price to drop out of the bidding, with dropping out being irrevocable. Winning bidders pay the price at which they have "clinched" an item and the process repeats until all units are allocated. For a better understanding of the allocation and payment rule of this mechanism, Table 1 includes an example of this auction with four identical objects to sell, $m=4$. There are three bidders, $n=3$, and their diminishing marginal values are given as follows: Bidder A: $v_{A, 1}=40, v_{A, 2}=35, v_{A, 3}=$ $30, v_{A, 4}=20$; Bidder B: $v_{B, 1}=40, v_{B, 2}=20, v_{B, 3}=15, v_{B, 4}=$ 10; Bidder C: $v_{C, 1}=25, v_{C, 2}=15, v_{C, 3}=10, v_{C, 4}=5$. These are marginal values for a first, second, third and fourth item, respectively.

TABLE 1

EXAMPLE OF AN AUSUBEL AUCTION PROCESS WITH DECREASING MARGINAL UTILITIES

\begin{tabular}{|c|c|c|c|c|c|}
\hline \multirow[t]{2}{*}{$\begin{array}{c}\text { Price } \\
\left(p^{l}\right)\end{array}$} & \multicolumn{3}{|c|}{$\begin{array}{c}\text { Quantities } \\
\text { demanded by } \\
\text { bidders }\left(q_{i}^{l}\right) \\
\end{array}$} & \multirow[t]{2}{*}{$\begin{array}{c}\text { Aggregate } \\
\text { demand } \\
\left(Q^{l}\right) \\
\end{array}$} & \multirow[t]{2}{*}{ Clinching of items } \\
\hline & $\mathrm{A}$ & $\mathrm{B}$ & $\mathrm{C}$ & & \\
\hline 0 & 4 & 4 & 4 & 12 & \\
\hline 5 & 4 & 4 & 3 & 11 & \\
\hline 10 & 4 & 3 & 2 & 9 & \\
\hline 15 & 4 & 2 & 1 & 7 & A "clinches" an item \\
\hline 20 & 3 & 1 & 1 & 5 & A "clinches" an item \\
\hline 25 & 3 & 1 & 0 & 4 & A \& B "clinches" an item \\
\hline
\end{tabular}

This example assumes that each bidder is going to bid according to his real values, sincere bidding. This means that bidders demand positive quantities as long as their values are lower than the standing price. Furthermore, demand is required to be non-increasing with price. At the initial price, $p^{l}=0$, the aggregate demand is $Q^{l}=12$, which is bigger than the available supply, $m=4$, so the auction must proceed further. The auctioneer begins to continuously increment the clock and price, and bidders submit their demands. The first important change occurs when the price reaches 15 . The aggregate demand at this price is 7 and the supply is 4 . Bidder A has now mathematically guaranteed himself at least one object as the aggregate demand of all competitors other than bidder $\mathrm{A}$ has dropped to 3. Bidder $\mathrm{A}$ has clinched winning an object for which he will pay 15 monetary units. The auction carries on and, as price goes up, bidders continue submitting their non-increasing demands. The auction ends when the price attains a level of 25 and bidder
$\mathrm{C}$ drops out of the auction reducing the aggregate demand to just 4 , thus equating demand with supply. With this last round the final outcome of the auction is that bidder A wins three objects for 15, 20 and 25 each and bidder B wins an object for 25 .

Each bidder's payoff is defined as the difference of his values of the units clinched minus the price paid per each item, i.e. the price at which they clinched. The revenue of the auction is defined as the total payment of each bidder for the units clinched. The payoff and revenues for the previous example are calculated below.

$$
\begin{aligned}
& \text { Payoff } \mathrm{A}=(40-15)+(35-20)+(30-25)=45 \\
& \text { Payoff } \mathrm{B}=(40-25)=15 \\
& \text { Payoff } \mathrm{C}=0 \\
& \text { Revenues }=15+20+25+25=85
\end{aligned}
$$

As price goes up and demanded quantities go down, it is possible that, for a certain increase of price, the supply is not covered at the final price. In these circumstances a rationing rule is applied. In this paper the proportional rationing rule has been considered.

In this auction format with pure private values and diminishing marginal utilities, Ausubel [12] states that sincere bidding is an ex post perfect equilibrium. Moreover, with no bid information sincere bidding is a weakly dominant strategy, i. e. it is the best strategy for a player no matter how that player's opponents may bid. However there is no theory model developed for increasing marginal utilities, so the equilibrium is unknown.

\section{THE GA THAT MAXIMIZE THE BIDDERS' PAYOFF}

A GA is a search algorithm based on the mechanics of natural selection and natural genetics. It is an iterative procedure which maintains a population of structures that represent candidate solutions for specific domain challenges. During each generation, the structures in the current population are rated for their effectiveness as solutions, and on the basis of these evaluations, a new population of candidate structures is formed using specific "genetic operators" such as reproduction, crossover, and mutation. Crossover and mutation are simple mechanisms for agents to modify their existing strategies, based on past experience. Crossover allows an individual to create a new strategy, by borrowing parts of previously successful strategies. Mutation allows an individual to make small modifications in old strategies, in hopes of finding something better.

In this work, all bidders bid according to the GA against their computer rivals learning from one auction to another. Players who fared well in the previous round will transmit the information to the other participants playing in the next round, those who fared poorly in the last round will observe which bidding strategies succeeded better and develop alternatives based on them. This task involves to the evolutionary dynamics of the model. Evolutionary dynamics can be imposed on the space of strategies by viewing strategies as interacting individuals in a population. These 
interactions represent the actions and reactions of the bidders in an auction. Through these interactions, each individual receives a score that represents its payoffs in the auction. The population dynamics is introduced in the model by letting successful strategies to have more offspring in next generations. In this schema those variations are generated by means of modifying the offspring by mutations, and generating new individuals-strategies by crossover. Here, like in many aspects of game theory, there is not a goal for the system to operate. All the individuals have their own goal: to have the greatest payoff. This approach could be claimed to be near the reality, where a set of bidders tries to optimize theirs payoffs. The final results could be understood as some equilibrium states, which any strategy could not beat in the same conditions. The study of that equilibrium is very interesting from two different points of view:

-- From the point of view of the bidders: to know which is the best strategy, and to have information of the risk of playing different alternatives.

-- From the point of view of the auctioneer: to know whether the rules used to sell theirs good are appropriate in terms of revenues and efficiency.

This work tries to analyse the Ausubel auction, when both decreasing and increasing marginal utilities are used. It also analyses what kind of strategies could be observed for each preferences, and if the equilibria could be founded.

\section{A. The experimental environments: decreasing and increasing marginal utilities}

Experiments have been designed with fifteen lots auctioned and four bidders with weakly diminishing marginal values and weakly increasing marginal values, risk neutral and no budget constraints (all variables are considered discrete). The bidders' behavior is explored without dropout information; bidders have no bid information, so they only know if the auction is still open.

All bidders have independent-private-values (IPV) that are privately observed by the respective bidders, making this an incomplete information game. For the diminishing marginal utilities, every bidder has a set of values organized from higher to lower which specifies the marginal value from the consumption of each additional unit. Bidders' values are drawn independently and identically distributed from a uniform distribution with support [0,200], with new random draws for each additional unit. These values are generated with the algorithm suggested by [10].

For the experiments with increasing marginal utilities, every bidder has a set of values organized from lower to higher that specify the marginal value from the consumption of each additional unit. Nevertheless, it is possible that the bidder reaches a certain number of items that satisfies his demand and so, he has a zero value for the remaining units. An example of these preferences distribution is presented below.

Bidder $i$ :

$$
v_{i, m}=(2,6,10,15,17,20,25,27,30,40,0,0,0,0,0)
$$

Bidders' values are also drawn independently and identically distributed from a uniform distribution with support $[0,10000]$ with new random draws for each additional unit. The experiments with increasing marginal utilities have been successfully tested with support $[0,200]$ and extended to $[0,10000]$ in order to add more variability to the test framework. The latest results are presented in the next section.

\section{B. Bidding strategy}

In each auction all bidders use a strategy codified in the chromosome of the individual that represents that bidder. The definition of the GA strategy suggested requires the identification of actions. Each action is defined in terms of deviations (over and underbidding) from the sincere bidding strategy. The demanded quantity according to the sincere bidding strategy of bidder $i$ in the round $l$ is represented by $q_{S B i}^{l}$. The bidders have thirteen possible actions to consider that are represented in Table 2. All these strategies have an upper bound that is the lowest of either the number of units being auctioned or, alternatively, the units demanded in the previous round (as demand is required to be non increasing). The lower bound is the number of units that the participant has already clinched. It is possible that some strategies lead to non integer numbers. In these circumstances the GA rounds up.

TABLE 2

EACH BIDDER CONSIDERS THIRTEEN POSSIBLE ACTIONS OR BIDDING STRATEGIES

\begin{tabular}{llcl}
\hline \hline $\begin{array}{l}\text { Strategy } \\
\text { number }\end{array}$ & $\begin{array}{l}\text { Action to } \\
\text { be taken }\end{array}$ & $\begin{array}{c}\text { If } q_{S B i}^{l}=1, \text { then } \\
\text { the strategy is: }\end{array}$ \\
\hline 0 & $q_{S B i}^{l} / 4$ & 0.25 & Underbidding \\
1 & $q_{S B i}^{l} / 3$ & 0.33 & Underbidding \\
2 & $q_{S B i}^{l} / 2$ & 0.50 & Underbidding \\
3 & $q_{S B i}^{l} / 1.75$ & 0.57 & Underbidding \\
4 & $q_{S B i}^{l} / 1.5$ & 0.67 & Underbidding \\
5 & $q_{S B i}^{l} / 1.25$ & 0.80 & Underbidding \\
6 & $q_{S B i}^{l} * 25$ & Bidding sincerely \\
7 & $q_{S B i}^{l} * 1.25$ & 1.00 & Overbidding \\
8 & $q_{S B i}^{l} * 1.5$ & 1.50 & Overbidding \\
9 & $q_{S B i}^{l} * 1.75$ & 1.75 & Overbidding \\
10 & $q_{S B i}^{l} * 2$ & 2.00 & Overbidding \\
11 & $q_{S B i}^{l} * 3$ & 3.00 & Overbidding \\
12 & $q_{S B i}^{l} * 4$ & 4.00 & Overbidding \\
\hline \hline
\end{tabular}

\section{The genetic algorithm mechanism}

The objective function that the GA tries to maximize is the payoff of each bidder. To this end, encoding the bidding strategies for the first experimental framework is a direct process. The thirteen possible actions can be encoded with four bits, (including the sincere bidding strategy, $q_{S B i}^{l}$ ). The assessment of the GA is made by running 10,000 auctions 
per experiment. The utility curves are initialized randomly for each experiment, but the bidders' type keeps constant for all the GA execution, this is, they have the same preferences for the 10,000 auctions. The search for the best strategy in each environment was performed using populations of four bidders. The parameters used in the experiments are reported in Table 3.

TABLE 3

PARAMETERS USED FOR THE EXPERIMENTS

\begin{tabular}{|c|c|c|}
\hline & & $\begin{array}{l}\text { Without dropout } \\
\text { information }\end{array}$ \\
\hline GA & $\begin{array}{l}\text { Canonical (SimpleGA } \\
\text { from GALib) }\end{array}$ & $\mathrm{N} / \mathrm{A}$ \\
\hline Population & 1 Population & 4 Individuals \\
\hline Encoding & Vector of bits & 4 bits \\
\hline Selection & Roulette & N/A \\
\hline Crossover & Single point & $100 \%$ \\
\hline Mutation & Flip bit & {$[1 . .0 .05] \%$} \\
\hline
\end{tabular}

\section{EXPERIMENTAL RESULTS}

In this section the outcome obtained by the GA strategy is analyzed. The experiments were run for the two environments described: decreasing and increasing marginal utilities, with fifteen items to be auctioned and four bidders. Revenues and efficiency of auctions as well as the bidders' behaviour and payoff have been studied. The revenues are measured as the monetary units that the seller gets after each auction. It has been compared the average actual revenue of each experiment with the one obtained if all bidders follow the sincere bidding strategy. An auction is considered to be efficient when it allocates the object to the bidder who values it the most ex post the auction. Therefore, for these experiments, efficiency is defined as the sum of the values of the fifteen units sold in an auction as a percentage of the sum the fifteen highest values in that auction. For the Ausubel auction and decreasing marginal utilities, efficiency is predicted to be $100 \%$, as in equilibrium, this is, bidding sincerely, it ensures full efficiency [18]. Therefore the average actual efficiency per experiment is compared to $100 \%$. For the increasing marginal values environment, a theory model has not been developed, so there is no reference for the predicted values. Therefore, full efficiency is also assumed (100\%) to do the comparison. Finally, the bidders' payoff and bidding strategy is analyzed in each environment.

\section{A. Results with decreasing marginal utilities}

The first step to analyse the auction outcome with the GA and decreasing marginal utilities is to study the bidders' behavior. To this end, the bidders' strategies for the first 2,700 auctions have been mapped in Figure 1, and bidding sincerely strategy is represented by one $\left(q_{S B i}^{l}\right)$. As the figure shows, bidders try all the possible strategies, mainly overbidding for the first iterations. Finally, as the logarithmic tendency line reports, bidders essentially bid sincerely (the 10,000 iterations have not been included in order to have a better understanding of the figure, but bidding sincerely continues being the stable strategy till the last auction). For these iterations, bidding sincerely is the strategy for the $76.07 \%$ auctions, being the ESS.

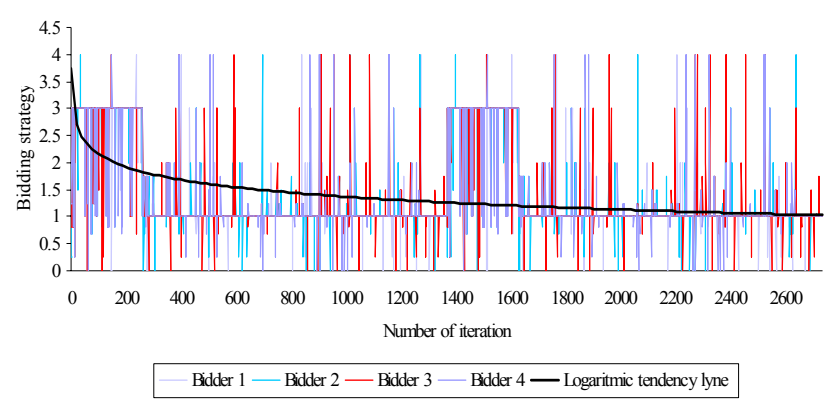

Fig. 1. Bidders' strategy with decreasing marginal values for the first 2,700 auctions. Each strategy is plot according to Table 2, column 3.

With this performance the revenues and efficiency outcome of the auctions is reported in Table 4. These data are compared with the predicted ones; this is, with the outcome if all bidders were to bid sincerely.

TABLE 4.

REVENUE AND EFFICIENCY ANALYSIS WITH DECREASING MARGINAL UTILITIES

\begin{tabular}{lrlr}
\hline \hline Revenues & \multicolumn{2}{l}{ Efficiency } & \\
\hline $\begin{array}{l}\text { Revenue with } \\
\text { sincere bidding } \\
\text { (units) }\end{array}$ & 11,384 & $\begin{array}{l}\text { Efficiency with } \\
\text { sincere bidding (\%) } \\
\text { Actual average } \\
\text { Actual average } \\
\text { revenue with the }\end{array}$ & $100 \%$ \\
$\begin{array}{l}\text { GA (units) } \\
\begin{array}{l}\text { Standard error of } \\
\text { the mean }\end{array}\end{array}$ & 12,697 & $\begin{array}{l}\text { GA (\%) } \\
\text { Standard error of the } \\
\text { Difference }\end{array}$ & $98.8 \%$ \\
$\begin{array}{l}\text { \% Difference } \\
\text { \% of iterations } \\
\text { that the GA yields } \\
\text { to the same } \\
\text { revenue as sincere } \\
\text { bidding }\end{array}$ & 1,313 & 0.0002 \\
\hline \hline
\end{tabular}

Revenues are measured as the monetary units that the seller gets after each auction. Efficiency is defined as the sum of the values of the fifteen units sold in an auction as a percentage of the sum the fifteen highest values in that auction. The average of both values is compared with the results if all bidders do sincere bidding (sincere bidding).

The actual average revenue with the GA is higher than the predicted one but this difference represents only the $12 \%$. The GA aims is to improve the bidders payoff. Therefore, all the bidding strategies are tested. As a result, when the bidding strategy differs from truthful bidding, the bidders are worst off, and therefore, the sellers' revenues are higher. $72.84 \%$ of the auctions yield to the same revenue that would be obtained if all bidders did sincere bidding. The average efficiency level is also very close to the predicted one (98.8\%) and $76.13 \%$ of the auctions yield to full efficiency. This difference is because the GA tries all the possible bidding strategies and because of the evolution and mutation effects. At the beginning all the strategies are settled randomly, and therefore correspond to bad strategies, and they tend to an equilibrium, as the evolution goes up. 
However, always new individuals are created with mutation operator.

The GA revenues for the last 1,000 iterations are represented in Figure 2. These values are also compared with the predicted ones. The figure shows that the sincere bidding revenues dominate when the GA is executed.

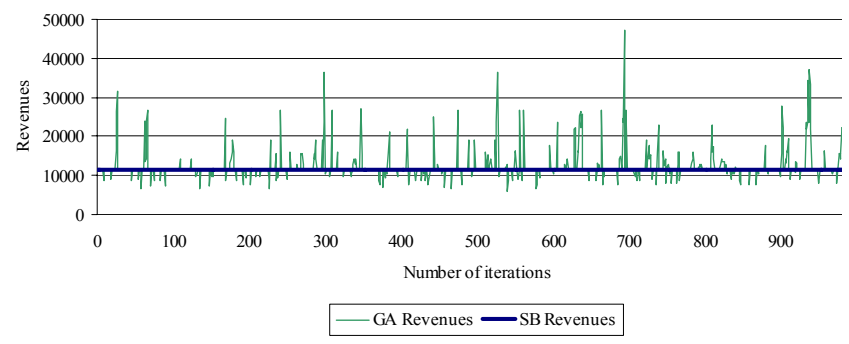

Fig. 2. GA and sincere bidding (sincere bidding) Revenues per iteration with decreasing marginal utilities for the last 1,000 auctions

The efficiency for the last 1,000 auctions of the 10,000 iterations run with the GA is mapped in Figure 3. The efficiency level is below one $(100 \%)$ but very close.

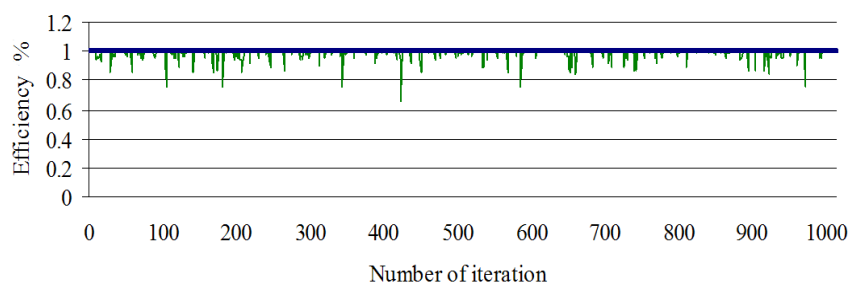

$$
\text { - GA efficiency } \longrightarrow \text { SB efficiency }
$$

Fig. 3. Efficiency per auction with decreasing marginal utilities for the last 1,000 auctions

Finally, the bidders' payoff is another convenient way to study the participants' behaviour. Table 5 includes the bidders' payoff if they all bid sincerely and the percentage of iterations that the bidders' strategy yield to the same payoff as bidding sincerely. The results reveal that bidders with the GA strategies are mainly getting the same payoff as with the sincere bidding strategy.

TABLE 5

BIDDERS' PAYOFF WITH DECREASING MARGINAL VALUES

\begin{tabular}{cc}
\hline \hline & $\begin{array}{c}\mathbf{N}^{\mathbf{0}} \text { times payoff } \mathbf{G A}=\text { Payoff sincere } \\
\text { bidding }\end{array}$ \\
\hline Bidder 1 & $73.69 \%$ \\
Bidder 2 & $73.60 \%$ \\
Bidder 3 & $72.88 \%$ \\
Bidder 4 & $74.00 \%$ \\
\hline \hline
\end{tabular}

Number of auctions or iterations that each bidder earns the same payoff as if all bidders do sincere bidding (sincere bidding).

Furthermore Figure 4 presents the difference payoff obtained by each bidder in each auction respect to the one obtained if all participants bid sincerely, for the last 1,000 auctions. As it shows bidders can either have higher and lower payoff but these situations are not stables. Deviations from the sincere bidding strategy can lead important losses for the bidders. No strategy overcomes truthful bidding for all bidders at the same time. Therefore, bidding sincerely, $i$. e. when the difference is equal to zero predominates across the iterations.

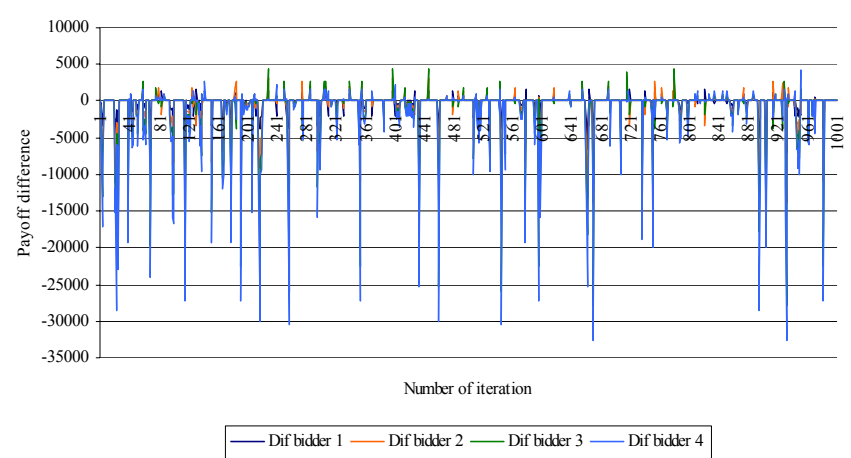

Fig. 4. GA bidders' payoff minus sincere bidding bidders' payoff with decreasing marginal utilities for the last 1,000 auctions

The GA has been tested in 50 experiments and in all of them the sincere bidding strategy has been reached as the ESS. Reference [12] established that sincere bidding is a weakly dominant strategy in the auction with no bid information and weakly decreasing marginal values. The GA has reached this weakly dominant strategy for the auction as the ESS.

\section{B. Results with increasing marginal values}

In the environment with increasing marginal utilities, the same variables have been tested. The bidders' bidding strategies for the first 1,000 iterations are represented in Figure 5. As it shows bidders try to maximize their fitness by over and underbidding. Nevertheless, the only stable strategy is to bid sincerely.

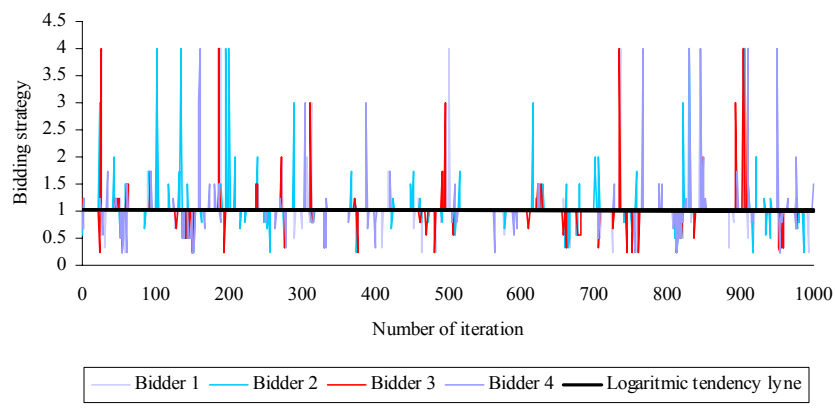

Fig. 5. Bidders' strategy with increasing marginal values for the first 1,000 auctions

The effect over revenues and efficiency is summarized in Table 6. The average revenues obtained with the GA are very close to those if all bidders were to bid sincerely in every round of each auction, the difference only represent a $2 \%$. Out of the 10,000 iterations, $75.12 \%$ yield to the same revenues as if all bidders do sincere bidding. As bidders are mainly bidding sincerely, the average efficiency level is also very close to full efficiency (92.9\%). Furthermore, $86.19 \%$ 
of the iterations gave in an efficiency level of $100 \%$.

TABLE 6

REVENUE AND EFFICIENCY ANALYSIS WITH INCREASING MARGINAL UTILITIES

\begin{tabular}{lrlr}
\hline \hline Revenues & & Efficiency & \\
\hline $\begin{array}{l}\text { Revenue with } \\
\text { sincere bidding } \\
\text { (units) }\end{array}$ & 76,660 & $\begin{array}{l}\text { Efficiency with full } \\
\text { efficiency (\%) } \\
\text { Actual average } \\
\text { efficiency with the GA } \\
\begin{array}{l}\text { Actual average } \\
\text { revenue with the }\end{array}\end{array}$ & $100 \%$ \\
$\begin{array}{l}\text { GA (units) } \\
\begin{array}{l}\text { Standard error of } \\
\text { the mean }\end{array}\end{array}$ & 74,752 & $\begin{array}{l}\text { Standard error of the } \\
\text { mean }\end{array}$ & $0.9 \%$ \\
$\begin{array}{l}\text { Difference } \\
\text { \% Difference }\end{array}$ & 83.15 & 0.002 \\
$\begin{array}{l}\text { \% of iterations that } \\
\text { the GA yields to the } \\
\text { same revenue as } \\
\text { sincere bidding }\end{array}$ & $2 \%$ & $\begin{array}{l}\% \text { Difference } \\
\% \text { of iterations that the }\end{array}$ & $7 \%$ \\
\hline \hline
\end{tabular}

Revenues are measured as the monetary units that the seller gets after each auction. Efficiency is defined as the sum of the values of the fifteen units sold in an auction as a percentage of the sum the fifteen highest values in that auction. The average of both values is compared with the results if all bidders do sincere bidding.

The revenues per auction for the last 1,000 iterations are represented in Figure 6. This figure just corroborates the intuition of Table 6. The GA strategy that dominates yields to the same revenues as if all bidders bid sincerely.

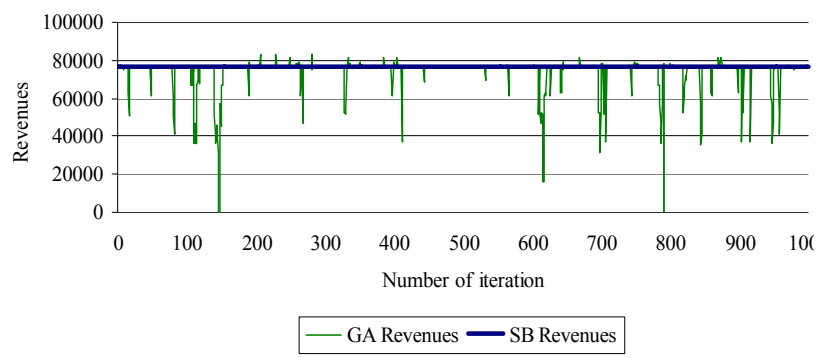

Fig. 6. GA and sincere bidding (sincere bidding) Revenues per iteration with increasing marginal utilities for the last 1,000 auctions

The efficiency analysis for the last 1,000 iterations is represented in Figure 7. Although the GA yields to some efficiency levels below $100 \%$, those strategies are not stable. Nevertheless, the strategy that dominates yields to full efficiency.

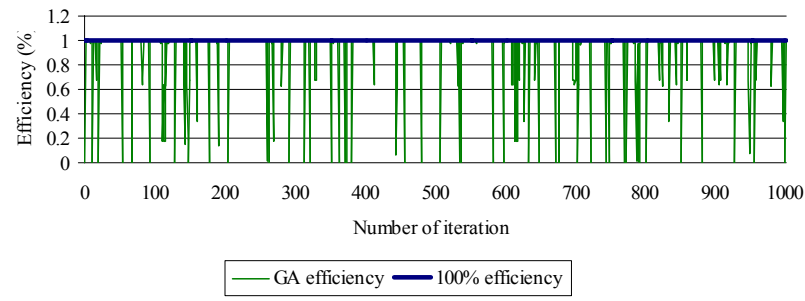

Fig. 7. Efficiency per auction with increasing marginal utilities for the last 1,000 auctions

The bidders' payoff is reported in Table 7. When bidders bid sincerely, those participants with the highest valuations are awarded the items. However, it is also possible for this strategy to earn negative payoff. With increasing marginal values, if one bidder does not clinch all the units demanded at the standing price, then his valuation can be lower than the total payment. In this circumstance he will have a negative payoff. Even so, the GA best strategy without dropout information is to bid sincerely. Bidders don't have information during the auction to respond to their rival's bids. As Table 7 shows, bidders are earning most of the times the same payoff as if they all bid sincerely.

TABLE 7

BIDDERS' PAYOFF WITH INCREASING MARGINAL VALUES

\begin{tabular}{cr}
\hline \hline & $\mathrm{N}^{\circ}$ times payoff $\mathrm{GA}=$ Payoff sincere bidding \\
\hline Bidder 1 & $94.91 \%$ \\
Bidder 2 & $84.18 \%$ \\
Bidder 3 & $95.41 \%$ \\
Bidder 4 & $75.07 \%$ \\
\hline \hline
\end{tabular}

Number of auctions or iterations that each bidder earns the same payoff as if all bidders do sincere bidding.

The difference of the payment that the bidders have obtained following the GA strategies with respect to what they would have obtained bidding sincerely is mapped in Figure 8 . As the figure reports the GA constantly search for new and better strategies. However, none but sincere bidding ends stable.

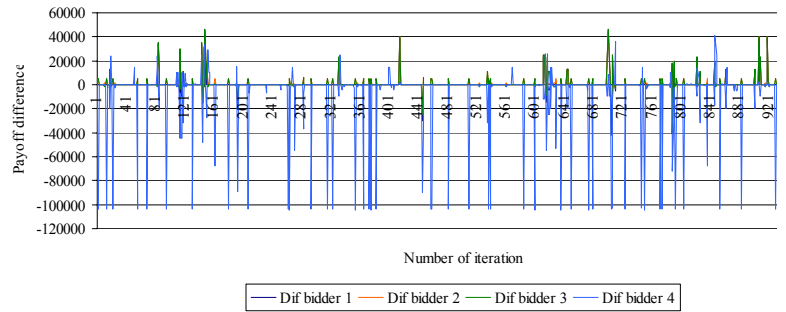

Fig. 8. GA bidders' payoff minus sincere bidding bidders' payoff with increasing marginal utilities for the last 1,000 auctions

The GA has been tested in 50 experiments within this environment. In all of experiments run bidding sincerely is the final ESS strategy. To determine that biding sincerely is an ESS for the Ausubel auction even when increasing marginal values are set up is a key finding. As there is no theory model developed for this assumption the predicted results were uncertain. Likewise, as bidders bid sincerely, the efficient allocation of the items remains.

\section{CONCLUSION}

This work is focused on a specific dynamic ascending multi-unit auction with implementation of Vickrey pricing, which is referred to as the Ausubel auction. The experiments have been carried out under an IPV framework and without drop out information. Besides, two environments have been considered according to the bidders' preferences: weakly diminishing marginal values and weakly increasing marginal values.

It has been developed a GA that can be successfully employed to evolve bidding strategies for this auction 
format. The GA aims to maximize each bidder's fitness, measured as the actual payoff. To this end, the algorithm generates thirteen different bidding strategies or actions defined in terms of deviations from the sincere bidding strategy: overbidding, underbidding or bidding sincerely. The experiments were run for fifteen items to be auctioned and four bidders. Each experiment was run for 10,000 iterations.

With decreasing marginal utilities and no bid information, [12] established that sincere bidding is a weakly dominant strategy and an ex post perfect equilibrium. In the 50 computational experiments developed the GA finds a strategy that finish finding the sincere bidding strategy as the ESS.

The main finding of this work is to have reached an ESS for bidders with increasing marginal utilities, as no theoretical model has been developed yet with this preferences assumption. In the 50 experiments run the algorithm reaches sincere bidding as the ESS. This result ensures full efficiency in the allocation of the items.

There are several directions in which the work presented could be extended. First of all, the GA results can be compared with a brute force algorithm testing all the search space $\left(4^{13}\right)$. Besides, the information rule established can have important implications finding the ESS. Therefore, it could be interesting to analyse the auction outcome assuming that there is drop out information during the auctions, this is, bidders have full bid information. Another challenge could be to find the ESS when the bidders' values are interdependent, this is, assuming common values. Additionally, the assessment of the sensitivity of the results to a wider range of combinations of number of bidders and items to be auctioned would also be of interest.

\section{REFERENCES}

[1] Dixit, A. and Skeath, S. 1999. Games of Strategy. W. W. Norton \& Company. New York. First Edition. 1-600.

[2] Holland, J. 1975. Adaptation in Natural and Artificial Systems, Ann Arbor. University of Michigan Press.

[3] Andreoni J., Miller J.H. 1995. Auctions with Artificial Adaptive Agents, Games and Economic Behaviour, 10, 39-64.

[4] Dawid, H. 1999, "On the convergence of genetic learning in a double auction market" Journal of Economic Dynamics \& Control. 23, 15451567.

[5] Numnonda, T and Annakkage, U. D. 1999. Optimal power dispatch in multimode electricity market using genetic algorithm. Electric Power Systems Research. 49 (3). 211-220.

[6] Wen, F.S and David, A.K. 2001. Strategic bidding for electricity supply in a day-ahead energy market. Electric Power Systems Research. 59 (3), 197-206.

[7] Anthony, P., Jennings, N.R. 2002. Evolving Bidding Strategies for Multiple Auctions. Proceedings of the $15^{\text {th }}$ European Conference on Artificial Intelligence. 178-182.

[8] Anthony, P., Jennings, N.R. 2003. Developing a Bidding Agent for Multiple Heterogeneous Auctions. ACM Transactions on Internet Technology. 3 (3), 185-217.

[9] Cliff, D. 2003. Exploration in evolutionary design of online auction market mechanisms. Electronic Commerce Research and Applications. 2 (2) $162-175$.
[10] Mochon, A. Quintana, D. Saez, Y. and Isasi, P. 2005. Analysis of Ausubel auctions by means of Evolutionary Computation. IEEE Congress on Evolutionary Computation 2005. 3. 2645-2652.

[11] Ausubel, L.M. 1997. An Efficient Ascending-Bid Auction for Multiple Objects. University of Maryland. Working Paper No. 97-06.

[12] Ausubel, L.M. 2004. An Efficient Ascending-Bid Auction for Multiple Objects. American Economic Review, 94, 1452-1475.

[13] Perry, M. and Reny, P.J. 2002. An efficient auction. Econometrica. 70 (3) $1199-1212$.

[14] Perry, M. and Reny, P.J. 2005. An Efficient Multi-Unit Ascending Auction. Review of economic studies. 72 (2) 567-592.

[15] Bikhchandani, S. and Ostroy, J.M. 2005. Ascending price Vickrey auctions, Games and Economic Behavior, to be published.

[16] Manelli, A. Sefton, M. Wilner, B. 2000. Multi-unit auctions: a comparison of static and dynamic mechanisms. Conference on applied research concerning auctions and mechanism design. University of Iowa.

[17] Vickrey, W. (1961) "Counterspeculation, auctions and competitive sealed tenders" Journal of Finance. XVI. 8-37.

[18] Kagel, J.H. and Levin, D. 2001. Behaviour in multi-unit demand auctions: experiments with uniform price and dynamic Vickrey auctions, Econometrica, 69 (2), 413-454.

[19] Kagel, J.H. Kinross, S. Levin D., 2004. Implementing efficient multiobject auctions institutions: an experimental study of the performance of boundedly rational agents. OSU Working paper 11/04.

[20] Kagel, J.H. Ye, L and Pevnitska, S. 2004. Survival auctions. Econometric Society 2004 North American Winter Meetings. No 414.

[21] Sunnevag, K. J. 2001. Auction design for the allocation of emission permits, Working Paper 5-01, UCSB.

[22] Dirk, E. and GrimmV. 2004,Bidding Behavior in Multi-Uni Auctions: An Experimental Investigation, IVIE Working Paper WP AD - 12

[23] Stigler, G.J and Becker, G.S. 1977. De gustibus non est disputandum. The American Economic Review, 67 (2) 76-90.

[24] Samuelson, P.A., and Nordhaus, W.D. 1985. Economics, New York. Mc Graw-Hill.

[25] Kahneman, D. and Tversky, A. 1979. Prospect Theory: An analysis of decision under risk. Econometrica, 47 (2) 263-292.

[26] Northcraft, G.B., Brodt, S.E., and Neale, M.A. 1995. Negotiation with nonlinear subjective utilities: why some concessions are more equal than others. Organizational Behavior and Human Decision Processes, 63 (3) 298-310. 